\title{
NUEVOS DATOS SOBRE LA HISTORIA DE LA SINAGOGA DEL TRÁNSITO
}

\author{
ANA MARÍA LÓPEZ ÁLVAREZ \\ SANTIAGO PALOMERO PLAZA \\ YASMINA ÁLVAREZ DELGADO
}

Museo Sefardí. Toledo

La sinagoga Samuel ha-Leví, más conocida como sinagoga de «El Tránsito", es un edificio característico del mudéjar toledano, que fue mandado construir en 1357, durante el reinado de Pedro I de Castilla, como agradecimiento a la gestión realizada por su tesorero y consejero don Samuel ha-Leví. Este personaje fue un hombre educado y culto, poseyó conocimientos de astrología y artes adivinatorias, fue administrador del caballero portugués don Juan Alfonso de Alburquerque y posteriormente pasó a ser nombrado tesorero real y a reorganizar la hacienda castellana; fue oidor de la Audiencia y diplomático, intervino en el tratado firmado entre Castilla y Portugal en 1358; en una ocasión salvó al rey de la prisión a la que le habían reducido sus hermanos bastardos, poniendo en peligro su vida por salvar la del rey; acusado de acumular tesoros y defraudar a su rey, fue sometido a tormento, a consecuencia del cual murió en 1360 '.

En las Crónicas de los Reyes de Castilla desde don Alfonso el Sabio hasta los Católicos Don Fernando y Doña Isabel leemos en el año once del reinado correspondiente a $1360^{2}$ :

"Como el don Pedro fixo prender a don Simuel el Levi su tesorero mayor, e d sus parientes:

En este año mesmo, é en estos días, el Rey despues que este fecho del Arzobispo pasó en Toledo, que le mando salir del Regno, 21.

1 A. M." López Álvarez, Catálogo del Museo Sefardi, Toledo, Madrid 1986, pág.

2 Crónicas... (Colección ordenada por Don Cayetano Rosell, publicada en Madrid por Atlas en 1953). 
segund avedes oido, luego donde á quatro dias mandó prender en Toledo á Don Simuel el Leví, su Tesorero mayor, é su privado, é del su consejo: é fueron presos él, é sus parientes en un día por todo el Regno. É ovo dél el Rey grandes tesoros, asi luego de los que falló en Toledo, como despues por tiempo. É segund se sopo por verdad, fueron falladas entonces á Don Simuel en Toledo ciento é sesenta mil doblas, é quatro mil marcos de plata, é ciento é veinte é cinco arcas de paños de oro é de seda, é otras joyas, é ochenta Moros é Moras é Moreznos. É ovo el rey de sus parientes de don Simuel trescientas mil doblas; como quier que decían algunos que lo más que se falló en sus parientes era de las rentas del Regno que ellos recabdaban por el Rey. É despues fué Don Simuel levado a Sevilla, é puesto en prision en la Tarazana, é ovo grandes tormentos por saber el Rey dél si tenía mas tesoros; é en fin destos tormentos ovo de morir. É fizo el Rey su Tesorero mayor á Martin Yañez de Sevilla luego que Don Simuel fué preso, é fueron todas las rentas é recabdamientos del Regno en su poder, ca él lo ordenó como quiso. E estovo el Rey en Sevilla lo que fincó deste año».

ETAPAS DE LA HISTORIA DEL EDIFICIO

1. Hasta la expulsión en 1492

Según la crónica de Rades Andrada, el rey don Pedro I

"dio licencia a los judíos que en Toledo vivían en su antigua Ley para que en aquella ciudad pudiesen fabricar de nuevo una sinagoga mayor, lo cual sin licencia no podian hacer, porque solamente les era permitido reparar y sustentar las antiguas sinagogas" ${ }^{3}$.

Tenemos muy pocos datos de la sinagoga durante el período que se utilizó como tal hasta el momento de la expulsión. Tan sólo las que podemos obtener a través de las inscripciones que denominamos "históricas" y que adornan los muros de la sinagoga. Son las alabanzas del cortesano hacia su rey.

«... magna águila de enormes alas, hombre de guerra y campeador,

${ }^{3}$ F. F. RAdes De Andrada, Chronica de las tres Ordenes y Cavallerias de Sanctiago, Calatraua y Alcantara, Toledo 1572, pág. 24. 
cuyo terror ha invadido a todos los pueblos grande es su nombre entre las naciones, el gran monarca, nuestro señor y nuestro dueño EL REY DON PEDRO..." 4 .

Asimismo, también existen en las mismas, frases de autoalabanza: "De genealogia de alcurnia y noble, de los nobles del país", "cimiento del imperio y el rango", "caudillo de la cautividad de Ariel", "columna diestra sobre la cual estriban la casa de Leví y la casa de Israel», "¿quién podrá enumerar sus alabanzas, cualidades y proezas?», "diadema del imperio", "príncipe de los príncipes del leviato, R. Šrmuel ha-Leví» s.

Asimismo, tenemos un poema de Yacaqob Albeneh dedicado a la revuelta antijudía que la aljama de Toledo sufrió en 1391. Escrito en forma de muwasaja habla de la ruina en que quedaron las sinagogas y las escuelas de formación religiosa. Enumera hasta diez sinagogas y cinco centros de estudio. Entre las primeras, menciona la «Sinagoga del príncipe Šmuel ha-Levi»»:

La sinagoga del príncipe Šmuel

ha-Leví, nasí de Israel,

grita: jay de Ariel!

Santo, que te asientas sobre las loas de Israel ${ }^{6}$.

No tenemos ninguna noticia en las crónicas cristianas de la sinagoga que, por sus dimensiones y belleza, es uno de los edificios medievales más importante.

En un documento, firmado el 25 de junio de 1492 en la Puebla de Guadalupe, que se encuentra en el Archivo municipal de Toledo, los Reyes Católicos disponen que no puedan vender los judíos antes de salir del reino ni las sinagogas, ni los osarios ni los bienes comunes de las aljamas. Hemos de suponer, al no existir ninguna noticia en contra, que los judíos utilizaron la sinagoga hasta el momento de la expulsión, porque en un documento firmado el 7 de julio de 1494

${ }^{4}$ F. CANTERA y J. M." Millas, Inscripciones hebraicas de Espanta, Madrid 1956, pág. 338.

5 Ibid.

${ }^{6}$ F. Cantera Burgos, Sinagogas españolas, con especial estudio de la de Córdoba y la toledana de El Tránsito, Madrid 1955, págs. 45 y 46. 
"el cardenal Mendoza, antes de acceder a la petición de la orden de Calatrava de dar licencia para bendecir como iglesia de la orden la antigua "sinagoga mayor" de los judíos, que les habían dado los reyes en equivalencia de la iglesia de Santa $\mathrm{Fe}$, que tenían entonces las monjas, pide al cabildo que le informen sobre la pertenencia de Santa $\mathrm{Fe}$ en el momento de la donación, y sobre unas cuestiones que surgieron hacía dos años, cuando por primera vez había hecho la misma petición de licencia la dicha orden de Calatrava y se les había denegado porque causaba perjuicio al cabildo y a la iglesia de Santo Tomé, en cuya colación estaba la sinagoga" ?

Por todo ello hemos de suponer que desde 1492 los Reyes Católicos entregaron la Sinagoga a los caballeros Calatravos.

\section{Desde 1492 hasta el siglo XIX}

Expulsados los judíos de España en 1492, los Reyes Católicos otorgaron a la Orden de Calatrava la

«sinagoga mayor que los judíos tenían en Toledo ... a cambio del Alcázar y palacios de Galiana con su iglesia de Santa Fe, posesiones de esta orden...",

tal como se recoge en la obra de Fray Francisco Rades de Andrada ${ }^{8}$.

Durante los siglos XV y XVI la antigua sinagoga pasó a ser templo y ermita de San Benito:

"Ay en la parroquia de Santo Tomé una hermita de San Benito, que es priorato de la orden de Calatrava, donde ay notables sepulcros y letreros, la cual se trasladó en iglesia christiana de Sinagoga ebrea, y aquí e significado podrían ser recogidos los clérigos débiles, biejos y mendicantes para que no fuesen con su miseria ofensores de tan alta dignidad"?.

7 P. León Tello, Judios de Toledo, Madrid 1979, tomo I, doc. 96, págs. 615-616.

${ }^{8}$ F. F. Rades ANDrada, op. cit., págs. 24 y 25.

9 C. VIÑAS REY y R. PAZ, Relaciones histórico, geogrófico estadistas de los pueblos de España hechas por iniciativa de Felipe II. Reino de Toledo, 2." parte, Madrid 1963, pág. 496. 


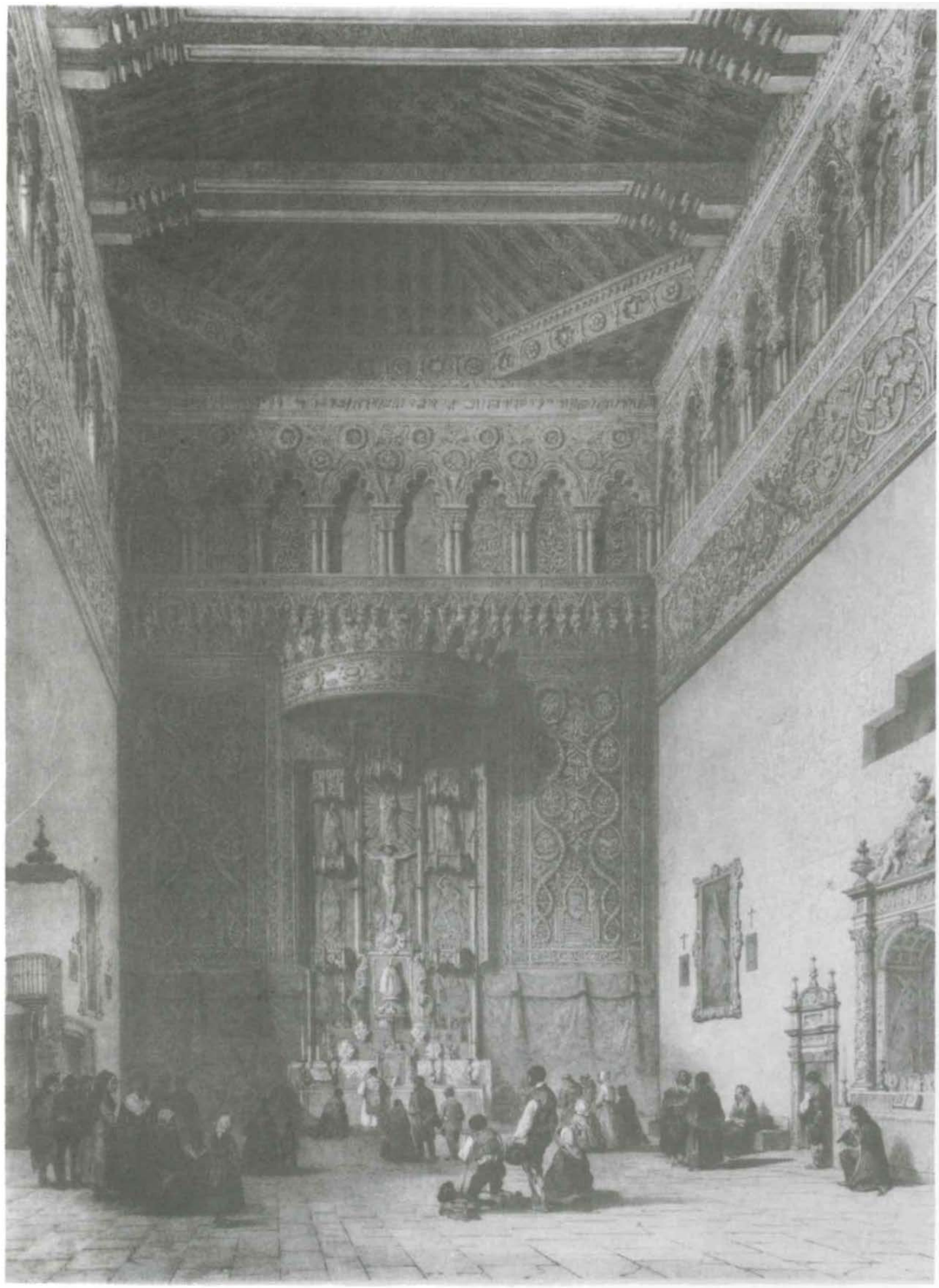

Iglesia de S. Benito Abad. Vulgo N. S. del tránsito (grabado de Villa-Amil, s. XIX)

(c) Consejo Superior de Investigaciones Científicas http://sefarad.revistas.csic.es 


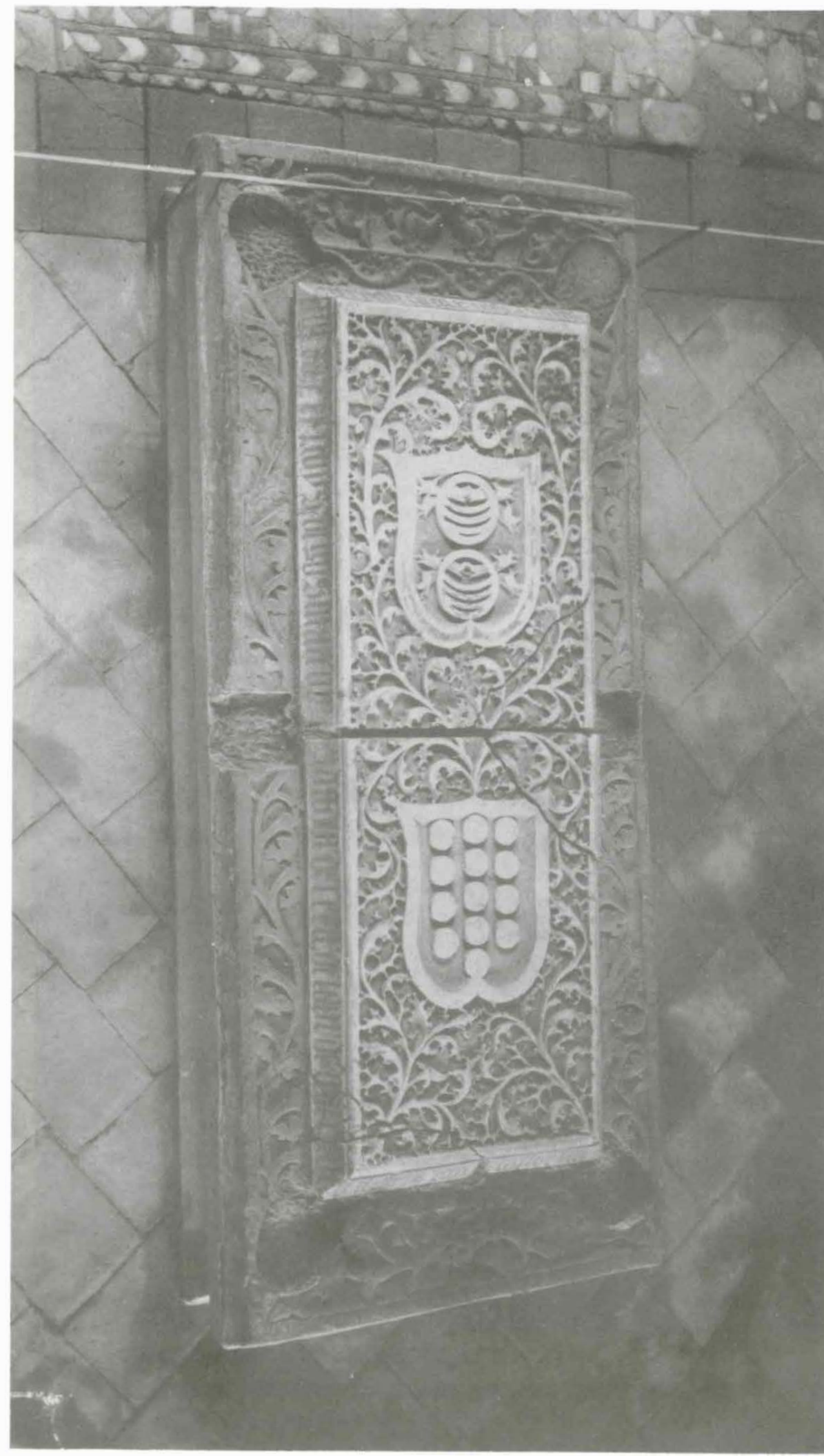

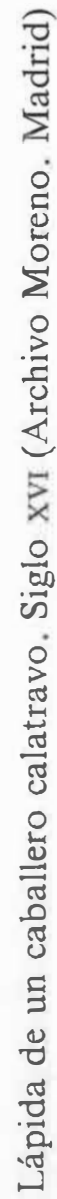

(c) Consejo Superior de Investigaciones Científicas 
Ésta sirvió en principio de asilo y cobijo de caballeros calatravos $y$ fueron enterrados algunos de ellos en este edificio:

«...y ya en su presencia se levantaron veinte y una losas de piedra de diferentes especies que sirben de memoria a los que en dicha yglesia estan sepultados gravadas en ellas, diferentes themas y rotulos que denominan las personas para quien se hicieron y no se encontro devajo de ninguna de las sepulturas vestigio alguno ni mas que tierra y cascotes y su merced mando a dicho maestro las bolviese a dejar en el mismo sitio que ocupaban y alzar de nuebo el solado..." ${ }^{10}$.

No hace muchos años todavía podían verse diecinueve de estas lápidas; algunas ilegibles, otras sin epitafio y un tercer grupo en que podían leerse nombres tan ilustres como los de "Freire Pedro de Silva, Comendador de Ojos, hizo de los Muy Magníficos Señores de Ribera", "Freire D. Grandi ... Caballero", "Comendador de la Fuente», «F. Tello Ramirez de Guzman, Comendador de Moratalaz, hijo de Ramiro Nuñez de Guzman...».

Abundan, entre los enterrados, miembros de la familia Guzmán, a los que identificamos por su escudo, y descendientes del Condestable de Castilla, don Alvaro de Luna ". Hoy estas lápidas se encuentran depositadas en el Museo de Santa Cruz de Toledo. En el nuevo montaje del Museo Sefardí se ha recuperado

"la del yllustre/ Señor Perafan de/Rivera Comenda/dor de las Casas de Toledo",

para recordar este período de la historia del edificio. Incluso a los pies de la sinagoga parece que existe una cripta en la que reposan los restos de unos personajes cuya filiación desconocemos, según nos han indicado personas que se encontraban presentes en las obras de los años sesenta.

Este edificio, dentro de la organización jerárquica de la Orden de Calatrava, tenía el rango administrativo de Priorato: en la docu-

10 AHN., Sección: Órdenes Militares (en adelante: Órdenes), Consejo: Orden de Calatrava, leg. 5224, fol. 68r, fechado entre 1734 y 1739.

$"$ P. Riera Vidal, Los judios de Toledo y sus sinagogas, Toledo 1958. 
mentación del Archivo Histórico Nacional, se cita el priorato de San Benito de Toledo, por ser la Orden afiliada al Císter.

Tenemos el documento en el que se detalla la primera visita del prior de San Benito y las actuaciones inmediatas que se habían de realizar en relación con la sacristía y con las inscripciones hebreas que adornan los muros del edificio:

"Yo frey domyngo de guebara comendador de las casas de to/ledo por my y en nombre de frey pedro Velez de juhan comendador / de calatrava la vieja visytadores generales de la hor/den y cavalleria de calatrava por los muy / altos e muy poderosos el Rey e la Reyna / nuestros sennores administradores perpetuos / de ella por bulla apostolica, hago saber a vos frey bernabe / prior de Sant benyto de la cibdad de toledo que visytando el dicho / vuestro prioradgo demas de las casas que en la dicha cibdad tiene / para que vos fue dada liçencia que las ençensarades e dieredes / a tributo perpetuo junto con un respaladar que esta a los espal/das de la iglesia de Sant Benyto. Se bieron otras casas que el dicho prio/radgo tiene en borox las quales estan algo mal tratadas especial/mente (han menester techado) la casa de mano derecha que ha menester enmade/rarse de buena madera e tejarse en manera que lo faga con lo otro / y reparar todos los tejados que juntan con la casa presyza por / que este sofriendo. Lo que os mando de parte de sus alteças y hagares / y complares e reparares da aquy al dia de Sant bartolome primero y lo visiteis / por que el patrimonio de la horden esta sofriendo/.

Otrosy mesmo vos mando que estedes residiendo en el dicho vestro / prioradgo y de vuestra disposicion. E los renones / en cada un conmo segund mandan las defynyçiones y asentares / en ellos tales e quales quier bienes ynmuebles/.

Otrosi mesmo por quanto por se utilidad de la yglesia se os dio licencia / para tributar el respaldar que esta tras el altar del ala en que entra la sacristia / que esta hecha. Vos mando que [emborronado] se haga el [tachado] tributo del dicho respaldar / hagares otra sacristia conmo entra la mano derecha atajando de su tabique / por donde con vos se platyco por que aya complimiento de la dicha sacristia pues es cosa tan neçesaria.

E otrosy hagares pues la tribuna en el cuerpo de la yglesya en la forma / e manera como con vos está consultado de su madera çepillada / blanca o conmo mejor pudieredes, junto con esto todos los / letreros que estan en la dicha yglesya asy en lo alto conmo en lo / baxo que son de letra judiega los hagares rapar e quitar / y 
tornar a blanquear y lo cual por que paresce cosa muy / nescesaria e sera servisio de dios. Vos mando que lo hagares e / complares desde el dia de la data de este mandamiento fasta / el dia de Sant Miguel primo de este de / anno en testimonio del visitador lo de frey de mi nombre e escrivano de mi visytacion / do mando escrivir en los libros de ella que es fecho primero dia / del mes de hebrero del dicho anno de mylle e quynientos" ${ }^{12}$.

Durante la restauración de las yeserías de la galería de mujeres, los restauradores del ICRBC del Ministerio de Cultura observaron que en la parte Norte de esta galería y en la zona más cercana a los pies de la sinagoga (aproximadamente en el ángulo SO) los caracteres hebreos aparecían rayados como si se hubiera querido destruirlos.

También llama nuestra atención al primer inventario de objetos que lleva la misma fecha:

«Sanct Benito de Toledo. 1 de hebrero de 1500 [signo] Inventario de los hornamentos e otras cosas que tyene la yglesya del prioradgo / del sennor Sant benyto de Toledo / Primeramente plata / Un caliz de plata con su patena blanco que pasa dos marcos / Una cruz de pye esmaltada con su crucifixo que pesa / tres marcos y una onça./ Una portapaz con la ymagen de una sennora esmaltada / y pesa tres marcos./ Una torre [iestamos ante uno de los rimmonim de la antigua sinagoga?] que pesa dos marcos e syete onças / e seis reales. / Un par de candeleros de plata que pesan dos marcos e cinco onças / Un ostiario de plata que pesa tres marcos e seys onças con / sus cadenas quatro. / Un par de anpollas de plata que pesan un marco y dos onças. / Una campanylla de plata que pesa un marco y una onça. / Yten una casulla de terciopelo negro con una cruz de raso colorado. / Otra casulla de raso blanco vieja con una cruz de raso negro. / Otra casulla de panno colorado guarneçida con oro del asan [?] [sic]./ Un frontal de terciopelo negro con una cruz colorada de raso. / Otro frontal de raso blanco viejo con una cruz de raso negra./ Otro frontal de panno de la misma casulla. / Una estola y un manípulo de terciopelo negro $=/$ Otro frontal de lienzo con una lavor morisca. / Una sabana de lino con unas cuantas naranjadas [?] [sic] viejas e un arca ca esta. / Toda esta plata y hornamentos sobre dichos es la capilla que tenía Luys de Guzman comendador de Murçia lo / qual los disponedores dieron para la dicha iglesia de sennor Sant benyto. / [verso] lo demas

${ }^{12}$ AHN., Órdenes, Consejo: Orden de Calatrava, leg. 6109, $\mathrm{n}^{2} 58$, fol. 50. 


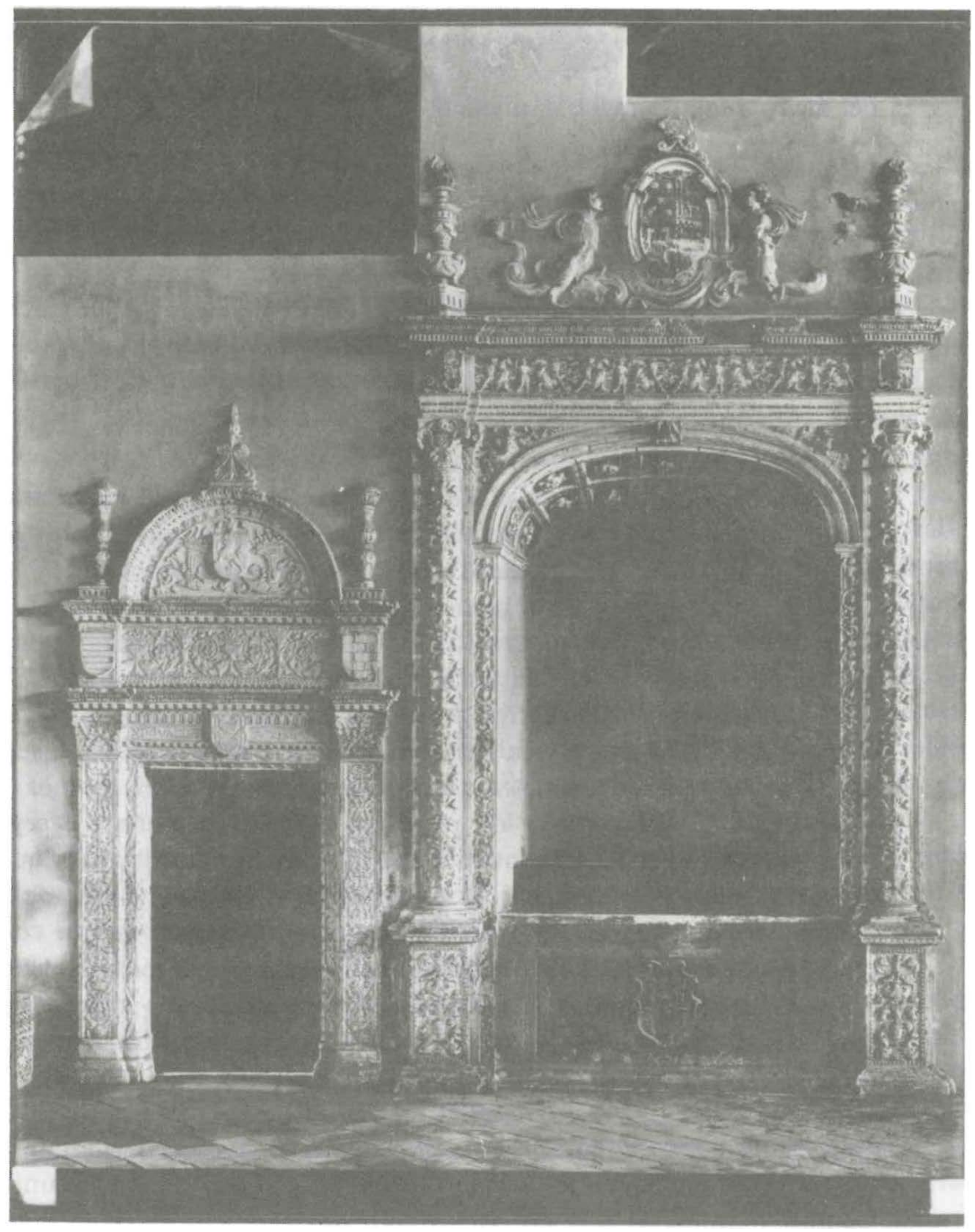

Puerta de la sacristía y altar donde se encontraba el cuadro del Tránsito de la Virgen.

(c) Consejo Superior de Investigaciones Científicas http://sefarad.revistas.csic.es 


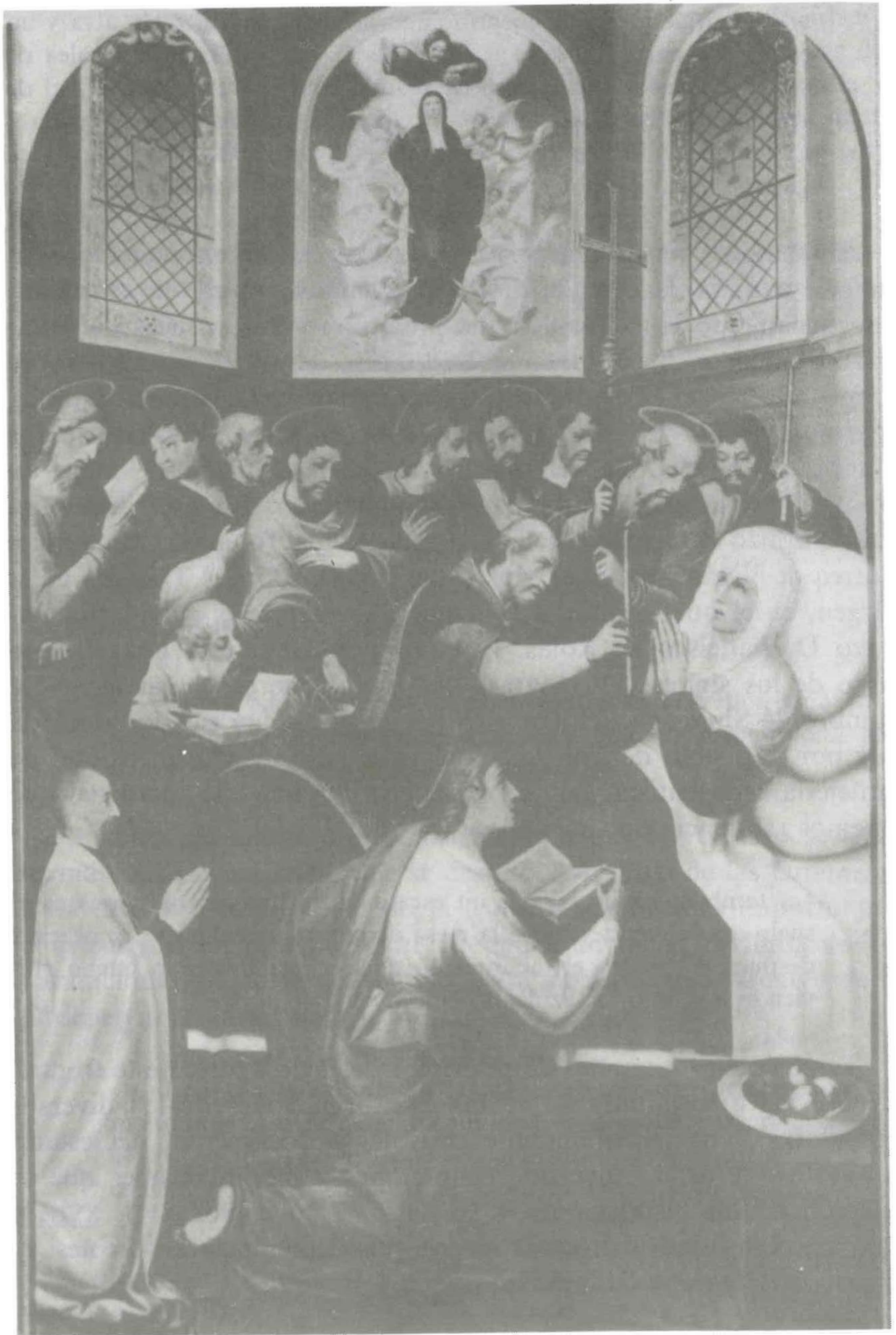

Juan Correa de Vivar: Tránsito de la Virgen (Museo del Prado)

(c) Consejo Superior de Investigaciones Científicas

http://sefarad.revistas.csic.es 
tyene la yglesia del dicho prioradgo de sant benyto. / Un alva y un avyto con cinta / un ara e dos pares de corporales / una palea de olanda labrada / un panno de olanda con sus recotaduras [sic] de seda para la paz / una savana de retanna con una cinta colorada / un guarda polvo para el altar / una campanilla de metal para quando alçan / una campana mediana de cinquenta libras" ${ }^{13}$.

El templo experimentó algunos cambios, construyéndose la «nueva sacristía» que se adornó con espléndida bóveda de terceletes, y se ornamentó con florones que presentan cuatro cruces de Calatrava doradas y una más, en su nudo, ésta de mayor tamaño, sobre la que se recorta un león rampante. En los vértices de la estrella, aparecen cuatro escudos, correspondientes a las familias de los Manrique, Lara, López Silva y Baztán. Tanto la puerta como un arcosolio están decorados en estilo plateresco. En este arcosolio, que se utilizó como altar, se encontraba el cuadro encargado a Juan Correa de Vivar, hoy en el Museo del Prado, sobre el Tránsito de la Virgen, en el que, orante, a la izquierda, aparece el caballero calatravo D. Fancisco de Rojas. El culto popular a esta imágen a lo largo de los siglos XVII, XVIII y XIX fue el que dió lugar al actual nombre de Sinagoga del Tránsito por el que sigue siendo conocida hoy por el pueblo de Toledo. El altar se adornó con un frontal de azulejería renacentista, hoy en paradero desconocido, pero del que tenemos referencia documental de los años 1734-1739:

«... tambien ha de revajar un escalon del altar mayor para que el suelo quede capaz y dar a la mesa del altar en ancho que se nezesite despues de puesto el tabernaculo que se esta haciendo nuebo volviendo a senttar los azulejos como oy esttan..." ${ }^{14}$.

También en fotografias de principios del siglo aparece este frontal.

Gracias a los libros de visitas e informaciones de los diversos visitadores, tenemos abundante constancia documental del estado del edificio y de las diversas reparaciones y modificaciones que se hicieron en sus instalaciones, a lo largo de los siglos XVII, XVIII y XIX, así como de los diversos inventarios de sus bienes muebles, es el caso de la galería de mujeres:

${ }^{13}$ AHN., Órdenes, Consejo: Orden de Calatrava, leg. 6109, $\mathrm{n}^{\circ} 58$, fol. 51r y v.

14 AHN., Ordenes, Consejo de Órdenes, leg. 5244, San Benito de Toledo, nombramientos y obras, fol. 39. 
«... En la bibienda alta se hallan dos piezas que sirben de Dormitorios y que estan sus techos maltratados ... la campana de la chimenea es preciso lebanttarla y componer el cañon de ella y a causa de ser la cocina oscura se necesita hacer una venttana de tres pies de altto y dos de ancho y una puerta del paso de dicha cocina y quartto..." 15 .

También sabemos a través de esta documentación que el suelo de la gran sala fue cambiado en varias ocasiones, una de ellas entre 1734 y 1739:

«... Que respecto de que uno de los reparos era el solar la Iglesia de nuevo y que en ella había dos ó tres sepulcros que levantavan como cuatro dedos del dicho solado ${ }^{16} \ldots$ Y por el respectivo al solado de la Yglesia y reparo que se halla de los dos ó tres sepulcros determino el Consejo que dicho solado se hiciese a nivel de los sepulcros" ${ }^{17}$.

Sobre el altar y los bancos:

“Como pintor que soy ... cincuenta reales de vellon ymporte de seis bancos, tres tarimas, un altar, una gradilla de pulpito ... todo dado de color negro ymitando a nogal» ${ }^{18}$.

Razones de índole económica hicieron que el Priorato se transformase en Encomienda, que se destinó a Archivo de las Ordenes de Calatrava y Alcántara, siendo la transformación más importante la construcción en el siglo XVIII de una gran nave, dividida en tres habitaciones, al norte del templo, para su uso como Archivo de las Ordenes de Calatrava y Alcántara:

"Una casilla azesoria a la iglesia de / dicho priorato que por maltratada / y de ninguna utilidad se demolio en/teramente y se acato [borroso] su suelo por / del priorato y en el año de mil se/iscientos noventa y cuatro se ejecu/to como consta de los autos

\footnotetext{
15 AHN., Ordenes, Consejo de Ordenes, leg. 5244, doc. 12, fechado en 1771.

${ }^{16}$ AHN., Ordenes, Consejo de Ordenes, leg. 5244, San Benito de Toledo, nombramientos y obras, fol. 2.

17 Ibid., fol. 4.

18 AHN., Ordenes, Consejo de Ordenes, leg. 5244, San Benito de Toledo, nombramientos y obras, 1769-1771.
} 
hechos / sobre reparos del beneficio que paran / en la escrivania de la Camara de Calatra/va y en cuyo sitio se fabrico el Archivo que oy tiene la orden en esta ciudad" 19.

En un documento de 27 de septiembre de 1738 tenemos noticia de graves deterioros en el tabernáculo motivados por la humedad:

«urgente necesidad de executarlos [los reparos], porque recalandose las paredes de la mencionada Yglesia, y casa Contigua a ella, con la continuación de las Aguas, se ha empezado ià hà experimentar alguna ruina, en tanto grado, que de lo inmterior del templo se desprendio un pedazo de la pared, y quasi redujo el tavernaculo, de forma que sino se ataja luego esta ruina, se puede seguir la que tambien amenaza a los Archivos nuevos" ${ }^{20}$.

En otro documento de 1794-1795 hay una clara alusión a los aljibes descubiertos en la excavación arqueológica llevada a cabo en el transcurso de las obras que se vienen realizando en la sinagoga de El Tránsito desde 1986. Estos pozos parece que tenían como misión proveer de agua potable a la comunidad judía de Toledo durante la Edad Media ${ }^{21}$. Al no haberse realizado una excavación arqueológica en el suelo de la sinagoga, no podemos decir si ésta se levanta sobre otra más antigua, ni si estos dos pozos pertenecieron a una miqweh contemporánea de la misma. Sobre este tema nos llama la atención lo que leemos en el siguiente documento:

"Sobre haverse opuesto un vecino a que se recojan en los pozos de dicha yglesia las aguas llovedizas.

Sr. Dn Antonio Ruiz, Diaz Presbitero encargado del cuidado de la casa e yglesia del priorato de San Benito ... dire a V. A. lo que he visto por mi mismo, con asistencia del arquitecto Josef albarez que me acompaño.

En el jardin que se halla en la casa de la Yglesia de Sn. Benito se encuentran dos pozos, los quales se hicieron sin duda para recivir el agua llovediza, mediante a lo que no se reconoce, que tengan manantial alguno y si se observa que la pared tiene a raiz de la tierra un bugero para la introducción de las aguas de los pozos y

\footnotetext{
19 AHN., Órdenes, Consejo: Orden de Calatrava, leg. 6027.

${ }^{20}$ AHN., Órdenes, Consejo de Órdenes, leg. 5244.

${ }^{21}$ I. Abraham, Jewish Life in the Middle Ages, New York 1981.
} 
[pliego 1r] quando estos revosan, se registran que de ellos sale, una especie de canal, que se halla cuvierto y tiene el desague fuera del poblado a la parte del rio ... La de una gran parte de la ciudad vaja por la calle de San Juan de Dios y por ella tiene su curso recto para el rio, ha sido por este presbítero y sus antecesores detenida con tablas $u$ otros materiales en la esquina del callejon llamado del Transito y encauzada halli, le ha ympedido el curso regular y le hacen tomarlo a la yzquierda, por el ynzinuado una llamada para el bugero, por donde se yntroduce en el Jardin y pozos ... [informe del Maestro de obras] ... dos pozos que se hallan en un Jardin contiguo á la Hermita de San Benito que denominan el Transito cuio Jardin tiene comunicacion á la casa del capellan de dicha Hermita y otra a un callejon: no ay memoria de la construccion de dichos pozos los que se surten de las aguas llovedizas que pasan por la calle y destilan sus canales haciendose para ello por el expresado Capellan un atajadizo en la calle con un poco de tierra que no sirve a los vecinos de ynpedimento y cosa que le es licito hacer pues aquellas aguas no llevan otro destino que el de ir al Rio, sin que se halla visto quitarselas a nadie y menos daña a otra casa pues se halla la dicha Hermita y Jardin esentas: las aguas de los referidos pozos se aplican para el gasto de la casa del Capellan y regar las plantas del jardin; sin que se advierta haver tenido mutacion alguna en tiempo alguno ni en su calle ni en los pozos por lo que juzgo no haver novedad..." 22 .

Estos documentos nos confirman que este patio, donde se ubican estos pozos, formaba parte de la iglesia de San Benito, antigua sinagoga, y que no fueron posesión de otros vecinos de la misma. Esta precisión es muy interesante porque ayuda a situar históricamente las dependencias encontradas por nosotros, carentes de documentación arqueológica, aunque habían sido excavadas anteriormente. Igualmente, nos está indicando la antigüedad de su construcción. Estos datos son de gran utilidad, ya que nos precisan las posesiones de la Orden en torno a la sinagoga en 1805:

«Iten la Escritura de venta otorgada por los herederos fideicomisos de D. Nicolas Revisco presbitero a D. Frey Antonio Cespedes Calderon de un Huerto que esta a espaldar de esta Iglesia en el callejon que vaja a San Juan de Dios izquierda su fecha nueve de mayo de 1780, ante Manuel Ximenez escrivano de este numero a la

${ }^{22}$ AHN., Órdenes, Consejo de Órdenes, leg. 3654, Caja 3." 7. 


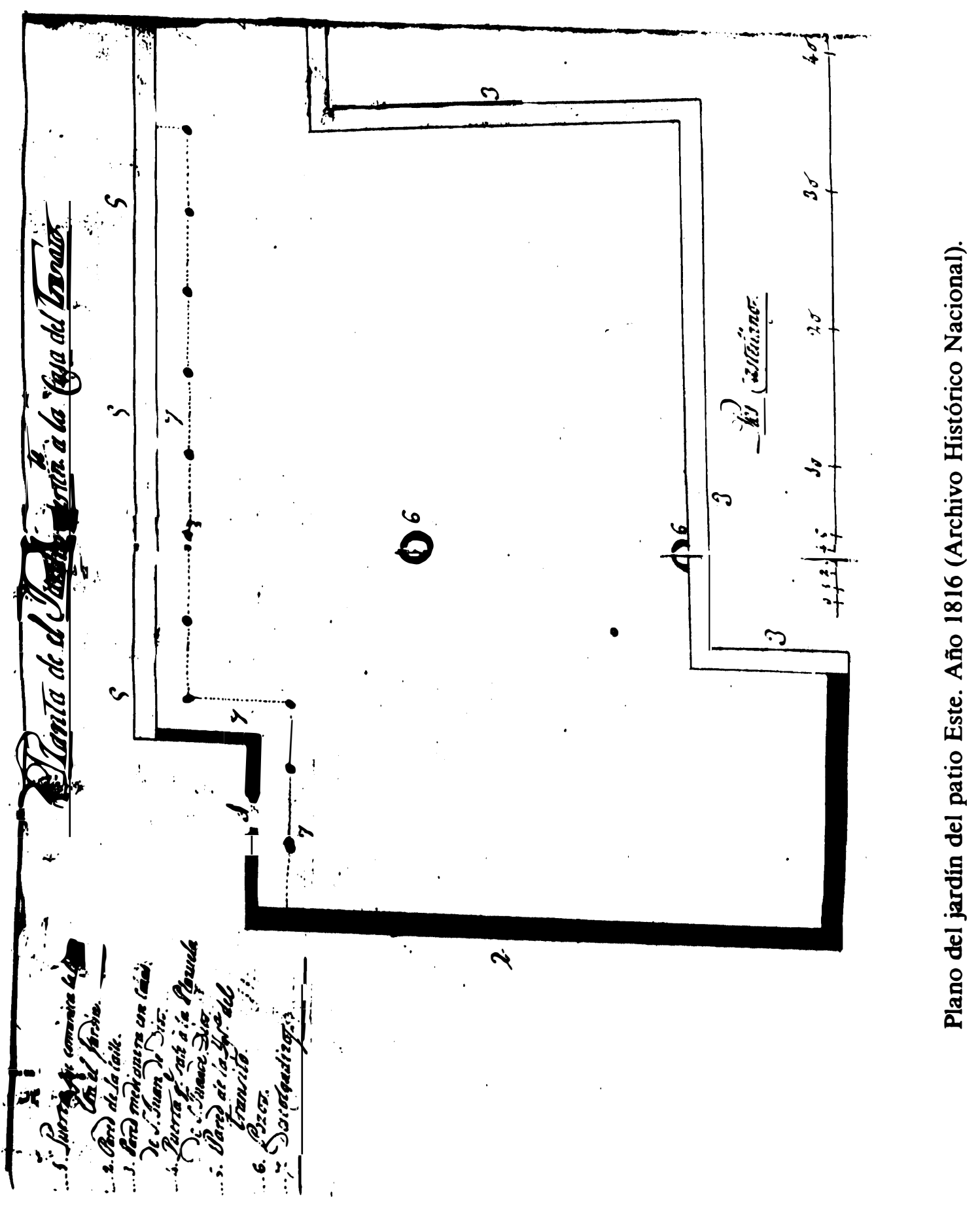




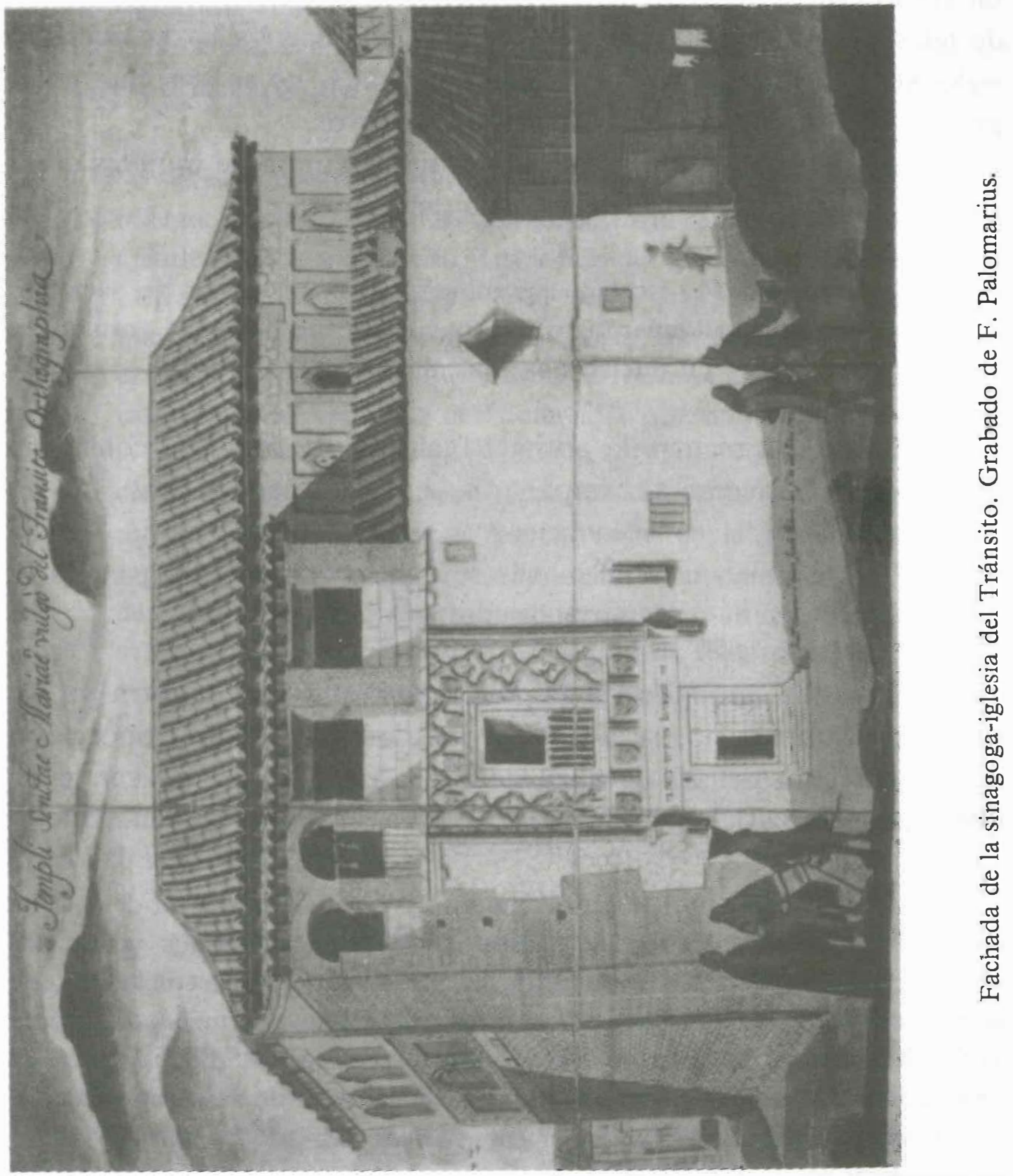


que esta unida otra escritura de venta de otro jardin por D. Juan Sanchez Rubio escrivano del Ilustrisimo Ayuntamiento" ${ }^{23}$.

En el dibujo de Francisco Palomares, que recoge el muro oriental tal como estaba en 1752, se aprecia el retablo cristiano y el aspecto de iglesia o ermita que mantuvo la antigua sinagoga hasta fines del siglo XIX. Al tratarse de una visión idealizada, no se aprecian en el grabado las tumbas de los caballeros calatravos.

La iglesia pasa a ser ermita y la antigua galería de mujeres de la sinagoga se habilita para ser vivienda del sacristán:

"Asimismo la escalera que sube a la tribuna y cassa del sacristan se necesita apeldañar y solarla por estar sus peldaños gastados y maltratados y sus guellas abarrancadas» ${ }^{24}$.

Dicha galería recorre la antigua fachada principal. Se construye una escalera de acceso al campanario, según leemos en 1763:

"Asimismo la escalera que sube a la galeria y campanario se necesita azerla por estar undiendose» ${ }^{25}$.

Por tanto el grabado de F. Palomares que nos muestra ya un primitivo campanario, se adecua a los datos que nos proporciona este documento del 29 de abril de 1763. En 1772 se realizan unas obras en la zona del campanario:

«... Ytem en el Mirador que está encima de la puerta de la calle hay cuatro huecos de ventana los dos forman arcos y los dos restantes tienen por unvrales las soleras de sus descolgadizos, de resulta que por tener estos claros siete pies de hueco se dornan dichas soleras, por lo qual se hace preciso cerrar dichos claros de tavique tablero rematado por ambos lados y de esta suerte queda dicho mirador mas usual» ${ }^{26}$;

${ }^{23}$ AHN., Ordenes, Consejo de Órdenes, leg. 6027. Referencia clara al patio del ala Norte.

24 AHN., Órdenes, Consejo de Órdenes, leg. 5243, 1763.

25 AHN., Ordenes, Consejo de Ordenes, leg. 5243.

${ }^{26}$ AHN., Ordenes, Consejo de Órdenes, leg. 5244, San Benito de Toledo, nombramientos y obras. 
es probable que cuando se hace esta modificación se pierda una de las dos vigas con inscripción hebrea que adintelaban los otros dos huecos, ya que en el grabado de Palomares de 1751 aparecen ambos con sus correspondientes vigas. En el siglo XIX se construirá la actual espadaña rematada con una cruz de Calatrava.

La ermita y el archivo sufren parejos la decadencia de las órdenes militares, deterioro que ya se dejaba notar a finales del siglo XVIII:

«Sin embargo [pliego 2] de todo esto a mi yngreso en el priorato indague la causa y medios de la existencia de SSmo. en su Hermita e halle ser esto a voluntad y expensas del dicho mi antecesor. Tengo un ynforme de 12 de Mayo de 1790 con relacion a este asupto en el que se dice sobre convenir a la honra y gloria de Dios la continuacion del Sacramento alli, por estar la Hermita sin culto en un barrio extraviado del comercio de la ciudad y que una escalera del uso de la casa da vista a la misma Hermita o capilla y le causan irreverencias. El cappn. dn. Antonio Ruiz me dijo en $1^{2}$ de noviembre del mismo año de la falta de concurrencia en la Hermita por estar separada del cuerpo de la ciudad: en 10 de octubre del 94 me aviso de haber amanecido sin rejas una de las ventanas y tube que costear otra: en 28 de septiembre de 1792 y 13 de febrero de este año, me aseguro que la Hermita estava situada afrentada entre muladares y todo inseguro" ${ }^{27}$.

Vemos además cómo los recursos económicos de la Orden son más bien exiguos:

«... parece que teniendo solo una Hermita extramuros e à los arrabales de Toledo que siempre se ha asistido y asiste por un Capellan y con havitacion ceñida para un santero y ninguna decente para el Prior careciendo en obcion directa en Diezmos y de encomendados residentes alli, estando tan dispersas las limitadas produziones del Priorato de manera que se cobran en Madrid, Aranjuez, Avila, Toledo, Granada y Almagro y faltando asi los medios para mi subsistencia en dicha ciudad" ${ }^{28}$.

${ }^{27}$ AHN., Ordenes, Consejo de Ordenes, leg. 3654, Caja 3a 6, doc. 5, expediente sobre reparos de la Hermita, 1794-1795.

${ }^{28}$ AHN., Ordenes, Consejo de Ordenes, leg. 3654, Caja 3.' 2, escribe en 1791 en el doc. $n^{2} 3$, D. Francisco Melgarejo sobre la obligación de residir en el Priorato. 
Y asimismo:

"Que por otra parte falta el motivo de la residencia del prior en Toledo por no vivir alli el Comendador, no haber cavalleros ni religiosos con quienes tener los oficios de la Difinición, ni habiendo alli tampoco bienes en que cuidar, ni cura de almas proxima ni remota que ejercer y habiendo variado todas las circunstancias que hacian oportuna la presencia del prior, à que se agrega que por estos motivos sin duda no se ha impuesto de inmemorial semejante obligacion de residir a sus antecesores" ${ }^{29}$.

En las guerras napoleónicas, la sinagoga-iglesia fue utilizada como barracón militar y sufrió nuevos daños. Tenemos noticias del progresivo despojo de la iglesia de Nuestra Señora del Tránsito, ligado a las vicisitudes que hemos reseñado:

«Serenisimo señor

La antiquisima Iglesia bajo la advocación de Ntra. Señora del / Transito en la ciudad de Toledo, propia del Priorato formado llamado / de Sn. Benito en la Orden de Calatrava y en ella custodiados dos / archivos, uno de la misma Orden y otro de la de Alcantara, se encuentran en estado mas lastimoso. El edificio tan deteriorado por sus tejados que introduciendose la agua cuando llueve menoscaban el precioso artesonado de todo el Templo que es de ebano; y el local de los Archivos recibiendo las aguas llovedizas que acaban con los papeles pero particularmente el mucho polbo que tienen encima los carcome hasta el punto que dentro de poco tiempo no podran leerse de un modo inteligible, si a esto como á lo demas no se acude con pronto remedio.

Las causas de haber llegado a un estado tan lastimoso estos memorables Monumentos erigidos á la gloria de las Ordenes Militares son faciles de descubrirse. El abandono culpable de Frey D. N. Raya, residente en Alhama, Reyno de Granada quien sin haber procedido a las Descripcion según derecho del Priorato para el que fue nombrado por los años 1831 á 32 y aun se ignora si á la prestación de fianzas, y a la mala inteligencia del Decreto de supresión de Regulares que se creyó haber comprendido en su sancion dicho Priorato con sus rentas. Asi fizo que Dn Pasqual Nuño primer Comisionado de amortizacion se apodero en la Iglesia de tres cuadros de mucho valor uno de Ntra Sa. del Tránsito original de Ticiano, otro que representaba el Santo Sepulcro y otro la venida del Espiritu Santo, estos dos pintados por un discipulo del

\section{${ }^{29}$ Ibid.}


primero, los cuales parece que existen en el Museo de la Trinidad de esta Corte.

Para aplicarse pues pronto remedio a tanto quebranto y proxima ruina en un Establecimiento tan respetable bajo muchos titulos juzgo indispensable que se adopten las medidas siguientes $=1 .^{a}$ que por de pronto se destine la cantidad señalada en la adjunta certificacion dada por un Maestro de obra de Toledo, sugeto de conocida honradez para que sin demora proceder á los reparos indicados: y como unos quinientos reales mas á efecto de que se limpien del polbo los papeles y el Archivo mientras que en mejor ocasion se le provea de Puertas para sus Estantes $=2 .^{a}$ que durante la ausencia de Toledo del que suscribe se autorice para que dirija estas obras al Caballero de la Orden de Alcantara residente en aquella Ciudad Dn. Miguel de Goenechea remitiendole el dinero al efecto y que se enteinda conmigo $=3 .^{2}$ que $\mathrm{V}$. e $\mathrm{T}$ [?] reclame del Gobierno la devolución de los Cuadros para cuya designacion de los que son se haga venir de Toledo oportunamente al Casero que cuida de la Iglesia cuya superintendencia habrá de comunicarse á dicho Caballero, mientras que Raya se presenta a examinar el estado de su Priorato. 4." que se oficie á este interrogandole si ha de cuidar de lo que le está encomendado en el particular y manifiesto cuales sean las rentas en el dia correspondientes al Priorato por que tengo entendido que el Heredamiento de Aranjuez debe contribuirle con ciertos granos, cuyo gravamen no ha caducado con la abolicion del diezmo como se hara demostrable en caso necesario y que bien Goenechea ú el Apoderado de Raya en Toledo Dn. Martin Gomez Recuero sugeto de conocida honradez conserven á disposicion del Tribunal un poco de plata [?] de la referida Iglesia que han podido salvar.

V. A. se dignara acordar sobre los puntos propuestos lo que tenga por mas acertado.

Madrid $1^{2}$ de marzo de 1845

[Firmado] Pedro Alfaro Ramon

(diligencia)

especial 6 de Mzo. de 1845.

Sres. Galdiano = Guillamar .

Oficiese al Prior formado D. [falta] Raya previniendole venga a Toledo a cuidar de lo que le corresponde, y que de lo contrario renuncie $=$

[Firma ilegible]". 
También la documentación del AHN sobre Órdenes nos proporciona, dada la minuciosa narración de todas las incidencias en cuanto se refiere a obras, curiosos comentarios:

«Expediente. Obras y reparos. Subastas y remate celebrado resuelto rematador el maestro Josef Alvarez en precio de 1338 reales con las condiciones propuestas ${ }^{30}$.

En el informe sobre la subasta ... la que se dexa sentada de composicion del Archivo, la de que en la guardilla del campanario, que se comunica por la casa se ponga una ventana fuerte con su cerradura y llave para cuitar la entrada de los muchachos a tocar y destrozar el texado, proporcionando que vagen las cuerdas de las campanas perpendicularmente y se les ympida la salida" ${ }^{3 !}$.

O aquel otro referente al capellán que cuida la ermita:

“... el capellan que cuida de la Hermita, o yglesia y havita la casa del priorato, homvre ya anciano, esta dotado de mui buenas cualidades y mucho celo por la devocion de Nuestra Señora, que se venera en dicha Hermita, con la advocación del Transito, pero no tiene otro negocio y continuamente esta molestando a el prior ponderando necesidades que no hai»" ${ }^{32}$.

O hablando de las ventanas del archivo nuevo:

«... respecto que dichos obalos tienen sus rejas y redes, para que no puedan introducirse paxaros ni otros animalejos que ocasionen perjuicio» ${ }^{33}$.

O la prevención de robos:

"Segundo, / poner una rexa carcelera en el cuarto baxo / para defender una ventana que esta proxima al piso de la calle, a fin de ebitar el ynsulto que / amenaza alas alaxas deplata que sirben al /

\footnotetext{
${ }^{30}$ No se pagará esta cantidad hasta que no se realicen las obras.

31 AHN., Ordenes, Consejo de Ordenes, leg. 5244, que contiene documentación fechada entre 1776 y 1803.

32 AHN., Ordenes, Consejo de Ordenes, leg. 5244, expediente 1798. Sobre reconocimiento de las casas del priorato.

33 AHN., Ordenes, Consejo de Ordenes, leg. 5243, San Benito de Toledo, nombramientos y obras, 1763.
} 
culto divino, mazizando asimismo, un gueco / que esta debaxo de la referida ventana" ${ }^{34}$.

Igualmente esta documentación nos da precisos detalles de las posesiones de la iglesia del Tránsito hasta el siglo XIX. En un documento de 1815 leemos:

“... resulta pertenezerle los bienes, rentas, diezmos y derechos siguientes. Ciudad de Toledo.

Casas [en el margen]. Primeramente pertenecen al priorato en la ciudad de Toledo, unas casas sitas en ella, contiguas a la yglesia de Nuestra Señora del Transito, propia tambien del mismo priorato, las cuales pareze se componen de diferentes oficinas altas y vaxas. Huerto del Jardin [en el margen]. Asimismo tiene un huerto jardin a espaldas de dicha Yglesia cercado de paredes con sus albardillas" ${ }^{35}$.

«Inventario de papeles.

Ytem la Escritura de venta otorgada por los herederos fideicomisarios de D. Nicolas Rebisca Presbitero D. Fr. Antonio Cespedes Calderon de un huerto que esta a espaldas de esta Yglesia en el callejon que vaja a S. Juan de Dios, mano izquierda, su fecha nueve de mayo de mill Setezientos y ochenta, ante Manuel Ximenez, Escribano de este numero, a la que esta unida otra escritura de venta de dicho jardin por D. Luis de Herrera a dicho presbitero ${ }^{36}$... Ytem se pone en Ynbentario el referido jardin, que esta a espaldas de esta Yglesia en el callejon que baja a la casa hospital de S. Juan de Dios el que parece lego y mando D. Fr. Antonio de Cespedes y Calderon en su testamento" ${ }^{37}$.

Esta documentación resulta de gran utilidad, pues gracias a ella podemos saber las propiedades que en la iglesia del Tránsito tenía la orden de Calatrava.

En un documento fechado en 1860 leemos:

\footnotetext{
${ }^{34}$ AHN., Órdenes, Consejo de Órdenes, leg. 5243, San Benito de Toledo, nombramientos y obras, 1772.

35 AHN., Órdenes, Consejo de Órdenes, leg. 3654, Caja n 1, Priorato de San Benito de Toledo. En el doc. $\mathrm{n}^{2}$ 1: "Certificación de los miembros, rentas y efectos de que es compuesto este priorato dada a Fr. Victoriano Fontecha, electo prior de él, para la formación de los autos de descripción y toma de posesión, 1815 w.

36 Ibid., fol. 8.

${ }^{37}$ Ibid., fol. 10.
} 
"Comisión de Monumentos Históricos y / Artísticos de la Provincia de Toledo - D. / Narciso Domingo Barsi, Vocal secretario de / la Comision Provincial de Monumentos / Historicos y Artisticos á que da nom/bre esta capital [signos notariales]= Certifico que / en el inventario de las pinturas y escul/turas pertenecientes a la Yglesia del / Transito de Ntra. Sra. de esta Ciudad / de Toledo, aparecen entre otras las seña/ladas con el numero cinco en tabla que / representa el Transito de Ntra. Sra. con todo el Apostolado, y a los pies un per/sonage del abito de Santiago: Sus dimen/siones tres varas alto por dos de ancho; / otra con el numero septimo y es un / cuadro apaisado del Jesucrito en el Se/pulcro del tamaño natural: de dos / varas y media de ancho por dos de / alto; y asi mismo la del numero ca/torce cuadro apaisado que indica la Venida del Espiritu Santo: de dos va/ras y media ancho por una y media / de alto; las cuales fueron traslada/das a la R. Academia de San Fernando / por el pintor de camara D. Juan Galvez, / Comisionado al efecto por expresada Rl. Aca/demia segun aparece del citado inv/entario y recibos firmados por el mencio/nado $\mathrm{Sr}$. Galvez en siete de julio de / mil ochocientos treinta y seis cuyos / documentos originales obran en esta / Sria. de mi cargo á que me remito. Y á los efectos oportunos de mandato / del Sr. Gobernador Civil de la Provincia / doy la presente visada por S. S. en con/cepto de Presidente de la Comision y á la cual se unirá el correspondien/te pliego de reintegro, en Toledo a ve/inte de julio de mil ochocientos cin/cuenta y nueve. Narciso Barsi $=V^{9} B^{9} /$ Huerta Murillo" ${ }^{38}$.

El documento va diligenciado para testimoniar su veracidad en 1860 y es respuesta a una solicitud cursada por D. Miguel de Goenechea, según documento de 16 de junio de 1860 que dirige al Sr. Dn. Alfonso de Cuenca, Secretario del Tribunal Especial de las Órdenes Militares:

«Para poder llenar con conocimiento los deseos del Tribu/nal Especial en Orden à averiguar el paradero de los / tres Cuadros que comprende la nota ... debo manifestarle para su inteligencia ... que habiendo adquirido noticias cier/tas de la pertenencia de estos Cuadros a la Iglesia del / Priorato formado de san Benito, bulgo el Transito en / que estavan colocados antes de trasladarlos à la Real / Academia de San Fernando en 7 de Julio de 1836 por el / Comisionado de la misma Dn Juan Galvez, Pintor de Camara; y no

${ }^{38}$ AHN., doc. expediente $n^{0} 1=262$ del folio "Comisión de Monumentos...». 
resultando en poder del representante del Prior / entonces Frey Dn Juan de Raya y Vinuesa ni recibo ni resguardo alguno, acudi al Governador Civil de esta / Provincia, Presidente de la Comision de Monumentos / Historicos y Artisticos con una esposición en 16 de julio del año proximo pasado del 59 que firmo el anterior / Eugenio Izquierdo en que haciendo relato circunstan/ciado de dichos cuadros se solicito la oportuna certificacion" ${ }^{39}$.

O es el caso, cuando ya se están desmontando las posesiones de los caballeros calatravos, del último inventario de las alhajas de plata,

«que se remitan al Tribunal Especial de las Ordenes Militares en cumplimiento de lo acordado por el mismo, transcrito en comunicación de cuatro de Junio ultimo, pertenecientes á la Iglesia del Priorato formado de San Benito de esta Ciudad de Toledo, Orden de Calatrava, a saver: una Lampara pequeña que pesa cuarenta y ocho onzas" ${ }^{40}$.

El 1 de mayo de 1877 el edificio fue declarado Monumento Nacional:

\section{$\mathrm{D} 0017 \mathrm{M}$}

$R$. O. de 1 de mayo de 1877, por la que se exceptúa de la venta de Bienes Nacionales, para que se conserve como Monumento histórico y artístico nacional:

El edificio conocido por Sinagoga del Tránsito, en la ciudad de Toledo.

Comienza entonces un rosario de diversas restauraciones, a cargo del Estado, que, desde finales del siglo XIX hasta el presente siglo, culminaron con la creación del Museo en 1964 y la remodelación definitiva, llevada a cabo desde 1985 hasta su nuevo montaje como Museo Nacional Sefardí, cuya apertura está prevista para la primavera de 1993.

\footnotetext{
39 AHN., doc. expediente $n^{\circ} 1=262$ del folio "para poder llenar con... $»$.

${ }^{40}$ Documentación del AHN., sobre las órdenes de Calatrava fechado el 7 de julio de 1864.
} 


\section{El siglo $X X$}

En el año de 1911 y merced a los buenos oficios del Marqués de la Vega Inclán, que, al ver el estado de ruina y de abandono en que se encontraba la sinagoga iglesia, se lo comunicó al rey don Alfonso XIII y al Presidente del Consejo de Ministros, don José Canalejas, buen amigo suyo, a quien se dirige el 27 de julio:

"exponiendo el estado en que se encuentra el edificio que fue en Toledo la sinagoga aristocrática fundada por Samuel Leví dedicada después a la devoción de la Virgen Santísima. Muy cercana al actual Museo de El Greco, esta sinagoga es el símbolo más acentuado de la influencia semita, junto con la sinagoga de la ciudad, muy próxima a ésta que lleva el título de Santa María la Blanca. Años hacía que para restaurar y decorar pictóricamente la armadura de la cubierta, el más preciado alfarje toledano, don Arturo Mélida, insigne arquitecto, pintor y escultor, levantó un gran andamiaje que ocultaba la maravillosa obra e inutilizaba por completo el monumento. Solicita de la Presidencia del Consejo se confie al Patronato del Museo de El Greco, la restauración de la sinagoga y su atención y conservación posterior, instalando en ella un centro de estudios hebraicos" ${ }^{41}$.

V. Traver añade:

"Tanto el Presidente del Consejo, como el Ministro de Instrucción Pública, don Amalio Gimeno, acogieron con entusiasmo la petición y autorizaron al Patronato para que, bajo la dirección del arquitecto don Eladio Laredo, procediese a desmontar el andamio y a restaurar el edificio. Se derribaron tabiques y obras postizas, descubriéndose atauriques y lacerías de preciado valor, quedando despejado el monumento para su contemplación. Adornado con grandes manojos de aromáticas hierbas, evocadoras de oriente, se entregó a la admiración de los numerosos visitantes que seguidamente comenzó a tener" ${ }^{42}$.

Por la Real Orden de 1 de septiembre de 1911, se incorpora al Patronato de las Fundaciones Vega Inclán, la sinagoga del Tránsito, quedando ese organismo encargado de su custodia y conservación. Nos llama la atención el artículo 5 de la R.O.:

41 V. Traver Tomás, El marqués de la Vega Inclán, Madrid 1965, págs. 116 y 117.

42 Ibid. 
«El Templo no podrá dedicarse nuevamente al culto cristiano ni tampoco se establecerá en él el israelita».

A partir del momento en que el edificio es incorporado a las Fundaciones Vega Inclán se procede a ultimar su restauración y el Marqués comienza a poner en práctica los puntos principales de la R.O. de 1911. Comienza a crearse un fondo bibliográfico de Hebraica y Judaica como base de lo que debería ser el Centro de Estudios Hebraicos que se mencionaba en esta orden.

El 9 de octubre de 1913, Alfonso XIII y el presidente de la república francesa $M$. Poincaré visitaron la ciudad de Toledo. Entre los monumentos que admiraron se encontraba la sinagoga. De esta visita queda constancia en el frontis de la puerta que da acceso a la gran sala, en el que aparece una inscripción conmemorativa:

«El Rey Don Alfonso XIII ordenó la consolidación y conservación de este monumento y el Patronato del Museo del Greco ejecutó la obra".

La historia del edificio hasta el momento de la creación del Museo Sefardí nos es poco conocida. Tan sólo algunas actividades, como conciertos, discursos, reuniones, se celebraron en su interior. Las referencias que nos han llegado nos hablan de obras de mantenimiento, como las realizadas en junio-julio de 1937 y que aparecen recogidas en el Boletín de Recuperación Artística y en el que se habla del "tejadillo de la entrada, colocación de cristales en los huecos exteriores...".

En el año de 1964, cuando se funda el Museo Sefardí, se ubica en su interior, porque

«no existe marco más adecuado que el venerable recinto de la Sinagoga de Samuel Leví, hoy conocida como Sinagoga del Tránsito ... para la creación de un Museo destinado a los testimonios de. la cultura hebraico española...",

según se dice en el decreto fundacional. Se pretendía de acuerdo con este decreto recoger los restos del pasado judío en España, así como los de aquellos judíos que, habiendo sido expulsados en 1492, conservaron su lengua y costumbres modificadas por la influencia de los países donde se establecieron y los que fueron asimilados por la 
misma. Son los que hoy conocemos con el nombre de sefardíes; nombre que también podemos aplicar a aquellos judíos que huyeron de España, sobre todo hacia Túnez, después de los trágicos sucesos de 1391.

En 1968 la Sinagoga se desvincula de las Fundaciones Vega Inclán.

El Museo se inauguró el 13 de junio de 1971. El intento de crear un Centro de Cultura Hebraicoespañola anejo al Museo, para el cual la familia Pinto donó el terreno, fracasó. Hoy en el edificio que debía cumplir estas funciones se encuentran los servicios de gestión y administración del Museo.

En este momento después de seis años (1986-1992) de obras de remodelación arquitectónica en la Sinagoga y en el Museo, en los que se han realizado diversas restauraciones de yeserías, artesonado, laudas sepulcrales y un nuevo proyecto museográfico, esperamos abrir de nuevo las puertas del Museo ubicado en el interior de la Sinagoga del Tránsito (las de la Sinagoga propiamente dicha han permanecido abiertas, salvo muy breves períodos, a lo largo de estos seis años) para mostrar los restos materiales de los judíos de España y su posterior diáspora sefardí.

\section{RESUMEN}

En este artículo se aportan, a la luz de una documentación inédita hasta el momento, los archivos de las Órdenes de Calatrava y de Alcántara, nuevos datos sobre la historia de la Sinagoga del Tránsito durante los cuatrocientos años en que fue utilizada como iglesia-ermita cristiana. Para comprender mejor la historia del citado edificio se ha dividido en tres períodos: $1^{9}$ ) desde su construcción hasta 1492; $2^{2}$ ) desde esta fecha hasta el siglo XIX inclusive; $3^{2}$ ) el siglo XX.

\section{SUMMARY}

This paper brings into light unknown documents from the Archives of the Orders of Calatrava and Alcantara which provide new data about the history of the El Transito Sinagogue during the four centuries it was used as a Christian chapel. For a better understanding of this history, three periods have been established: 1) from the date it was built up to $1492 ; 2$ ) from 1492 to the 19 th century; 3 ) the 20th century. 